\title{
Mario Kozah, Abdulrahim Abu-Husayn, Saif Shaheen Al-Murikhi, Haya Al Thani (eds). The Syriac Writers of Qatar in the Seventh Century
}

Florence Jullien

\author{
(2) OpenEdition \\ Journals \\ Édition électronique \\ URL : https://journals.openedition.org/abstractairanica/45193 \\ DOI : 10.4000/abstractairanica.45193 \\ ISBN : 1961-960X \\ ISSN : 1961-960X \\ Éditeur : \\ CNRS (UMR 7528 Mondes iraniens et indiens), Éditions de l'IFRI
}

\section{Référence électronique}

Florence Jullien, « Mario Kozah, Abdulrahim Abu-Husayn, Saif Shaheen Al-Murikhi, Haya Al Thani

(eds). The Syriac Writers of Qatar in the Seventh Century », Abstracta Iranica [En ligne], Volume 37-38-39 |

2018, document 35, mis en ligne le 30 décembre 2018, consulté le 21 septembre 2021. URL : http://

journals.openedition.org/abstractairanica/45193; DOI : https://doi.org/10.4000/abstractairanica. 45193

Ce document a été généré automatiquement le 21 septembre 2021.

Tous droits réservés 


\section{Mario Kozah, Abdulrahim Abu- Husayn, Saif Shaheen Al-Murikhi, Haya Al Thani (eds). The Syriac Writers of Qatar in the Seventh Century}

Florence Jullien

\section{RÉFÉRENCE}

Mario Kozah, Abdulrahim Abu-Husayn, Saif Shaheen Al-Murikhi, Haya Al Thani (eds). The Syriac Writers of Qatar in the Seventh Century. Piscataway: Gorgias Press, 2014, 298 p. ISBN 978-1-4632-0355-9, (Gorgias Eastern Christian Studies 38)

1 Cet ouvrage fait suite à un colloque tenu à Qatar University (Doha) en partenariat avec l'Université américaine de Beyrouth en 2014, dans le cadre d'un programme de recherche financé par le Qatar National Research Fund. Il se propose de jeter des bases pour des recherches futures sur l'aire du Bēth-Qațrāyē durant l'Antiquité tardive et au début de l'islam. Le VII siècle fut une période étonnamment prolifique et riche pour l'histoire monastique et littéraire syriaque dans le Bēth-Qațrāyē. Nombre d'auteurs ascétiques, originaires de cette région du Golfe ou qui y furent formés, furent considérés comme des maîtres spirituels de premier plan, dont l'influence, notamment sur la vie monastique et mystique, se prolongea au-delà des siècles. Sans doute le monastère de Rabban Šābuhr joua-t-il un rôle central dans la formation spirituelle et ascétique de ces moines du Qatar (voir F. Jullien, «Rabban-šāpūr, un monastère au rayonnement exceptionnel. La réforme d'Abraham de Kaškar dans le Bēth-Hūzāyē », Orientalia Christiana Periodica 72, 2006, p. 333-348).

2 Après une introduction qui expose les principaux jalons de l'entreprise (M. Kozah, p. 11-32), le livre collectif s'ouvre par une utile présentation des vestiges archéologiques retrouvés dans cette région du golfe Persique (H. Al Thani, «An Archaeological Survey 
of Beth Qatraye ", p. 33-46), et par un panorama historique du christianisme en Arabie entre le IV e et le IX ${ }^{\mathrm{e}}$ s. (S. A. Mourad, "Christianity in Arabia: An Overview (4th-9th Centuries (E)», p. 47-70). A. R. Chamseddine analyse ensuite le terme coranique de hanif (adepte du monothéisme abrahamique), à la lumière de la documentation syriaque ("The Quranic Word hanif and its Explanation in the Light of the Syriac Root ", p. 71-80). Trois études sont dévolues à la figure monastique et mystique syroorientale la plus influente, celle d'Isaac de Ninive : G. Kessel réalise une recension très commode de tous les manuscrits syriaques de cet auteur magistral («The Manuscript Heritage of Isaac of Nineveh: A survey of Syriac Manuscripts », p. 81-102) ; M. Hansbury effectue une analyse des influences bibliques et scripturaires dans la $\mathrm{III}^{e}$ partie de l'œuvre d'Isaac, issues notamment les traditions juives et islamiques (« Remembrance of God and its Relations to Scripture in Isaac III Including insights from Islamic and Jewish Traditions », p. 103-132); S. Chialà s'intéresse à l'approche apocatastatique de l'évêque de Ninive dans deux discours de la $V^{e}$ partie, soulignant l'importance de l'expérience spirituelle personnelle de l'auteur dans ces positionnements («Two Discourses of the "Fifth Part" of Isaac the Syrian's Writings: Prolegomena for Apokatastasis? » p. 133-142). D’autres écrivains moins connus sont présentés : Ahūb du Qatar, un exégète biblique (B. ter Haar Romeny, «Syriac Biblical Interpretation from Qatar: Ahob of Qatar », p. 143-164), et Gabriel du Bēth-Qațāyē, témoin et exemple du développement et de la richesse de la vie intellectuelle des chrétiens syriaques au tournant du VII e siècle (S. P. Brock, "Gabriel of Beth Qatraye as a Witness to Syriac Intellectual Life c. $600 \mathrm{CE}$ », p. 165-178). Comme en écho, l'étude de T. A. Carlson fait le point sur la réception de ces auteurs syriaques qațrāyē en Iraq à l'époque médiévale tardive, montrant ainsi la pérennité de l'impact de ces auteurs dans les milieux culturels ("The Future of the Past: The Reception of Syriac Qatraye Authros in Late Medieval Iraq ", p. 179-204). Puis viennent trois contributions, la première sur l'une des œuvres les plus connues du célèbre Dadīšo` Qațrāyā, son commentaire abrégé du Paradis des Pères d'Égypte: M. Kozah, chargé de l'édition du texte en garshuni, en présente les grandes lignes ("Dadisho' Qatraya's Compendious Commentary on the Paradise of the Egyptian Fathers in Garshuni - A Case of Manuscript Mistaken Identity ", p. 205-216); dans la seconde, D. Phillips montre l'influence des écrits de Théodore de Mopsueste, l'Interprète par excellence pour les chrétiens syro-orientaux, dans l'ouvrage de Dadī̌̌ō ("Lost and found: Dadisho' Qatraya's Commentary on the Paradise of the Fathers as a witness to the works of Theodore of Mopsuestia», p. 217-240). La troisième, de R. A. Kitchen, étudie les liens entre le monachisme d'Ethiopie et les développements du monachisme dans le Bēth-Qațrāyē ( $«$ The Book of Monks: Ethiopian Monasticism via Beth Qatraye », p. 241-258).

3 L'ensemble se clôt par une réflexion sur l'influence du christianisme parmi les tribus arabes du pourtour du Golfe durant les $\mathrm{VI}^{\mathrm{e}}$ et VII ${ }^{\mathrm{e}}$ siècles (S. S. Al-Murkihi, "The Influence of Christianity Among the Arab Tribes in the Gulf Area During the Sixth and Seventh Centuries A.D.», p. 259-278), suivie d'une bibliographie fournie sur la thématique. Ce volume s'accompagne d'un second tome complémentaire, qui formera une anthologie des grands textes des auteurs du Bēth-Qațrāyē; la publication est prévue pour 2016. Signalons, des mêmes éditeurs, An Anthology of Syriac Writers from Qatar in the Seventh Century, (Gorgias Eastern Christian Studies 39), Piscataway: Gorgias Press. 


\section{AUTEURS}

\section{FLORENCE JULLIEN}

CNRS, Mondes iranien et indien, Paris 